\title{
Effects of nebulized epinephrine in association with hypertonic saline for infants with acute bronchiolitis: a systematic review and meta-analysis
}

\author{
Renan Pereira ${ }^{1}$, Versiéri Almeida ${ }^{1}$, Mariana Zambrano ${ }^{1}$, Linjie Zhang $^{2}$, and Sérgio \\ Amantéa ${ }^{1}$ \\ ${ }^{1}$ Universidade Federal de Ciências da Saúde de Porto Alegre \\ ${ }^{2}$ Universidade Federal do Rio Grande
}

May 16, 2021

\begin{abstract}
Management of acute bronchiolitis remains controversial due to lack of strong evidence-based data. Nebulized epinephrine and hypertonic saline have been studied in infants with bronchiolitis, with conflicting results. This systematic review and meta-analysis aimed to evaluate the efficacy on length of stay (LOS), clinical severity scores (CSS), oxygen saturation (SaO2) and safety profile of nebulized epinephrine plus hypertonic saline (HS) in infants with acute bronchiolitis. Outcomes were represented by mean differences (MD) or standard mean differences (SMD) and $95 \%$ confidence intervals (CIs) were utilized. 18 trials were systematically selected and 16 of them contributed for the meta-analysis (1,756 patients). Overall, a modest but significant positive impact was observed of the combination therapy on LOS (MD of -0.35 days, $95 \%$ CI -0.62 to -0.08 , p $=$ $0.01, \mathrm{I} 2=91 \%$ ). Stratification by time of CSS assessment unveiled positive results in favor of the combination therapy in CSS assessed 48 hours and 72 hours after the admission (SMD of $-0.35,95 \%$ CI -0.62 to $-0.09, \mathrm{p}=0.008$, I2 $=41 \%$ and SMD of $-0.27,95 \%$ CI -0.50 to $-0.04, \mathrm{p}=0.02$, I2 $=0 \%$, respectively). No difference in $\mathrm{SaO} 2$ was observed. Additional data showed a consistent safety profile, with a low rate of adverse events (1\%), most of them mild and transient. In conclusion, nebulized epinephrine plus HS may be considered as a safe, cheap and efficient alternative for decreasing LOS and CSS in infants with acute bronchiolitis, especially on those who require more than 48 hours of hospitalization.
\end{abstract}

\section{Hosted file}

Effects of nebulized epinephrine in association with hypertonic saline for infants with acute bronchiol available at https://authorea.com/users/414005/articles/522155-effects-of-nebulizedepinephrine-in-association-with-hypertonic-saline-for-infants-with-acute-bronchiolitisa-systematic-review-and-meta-analysis 


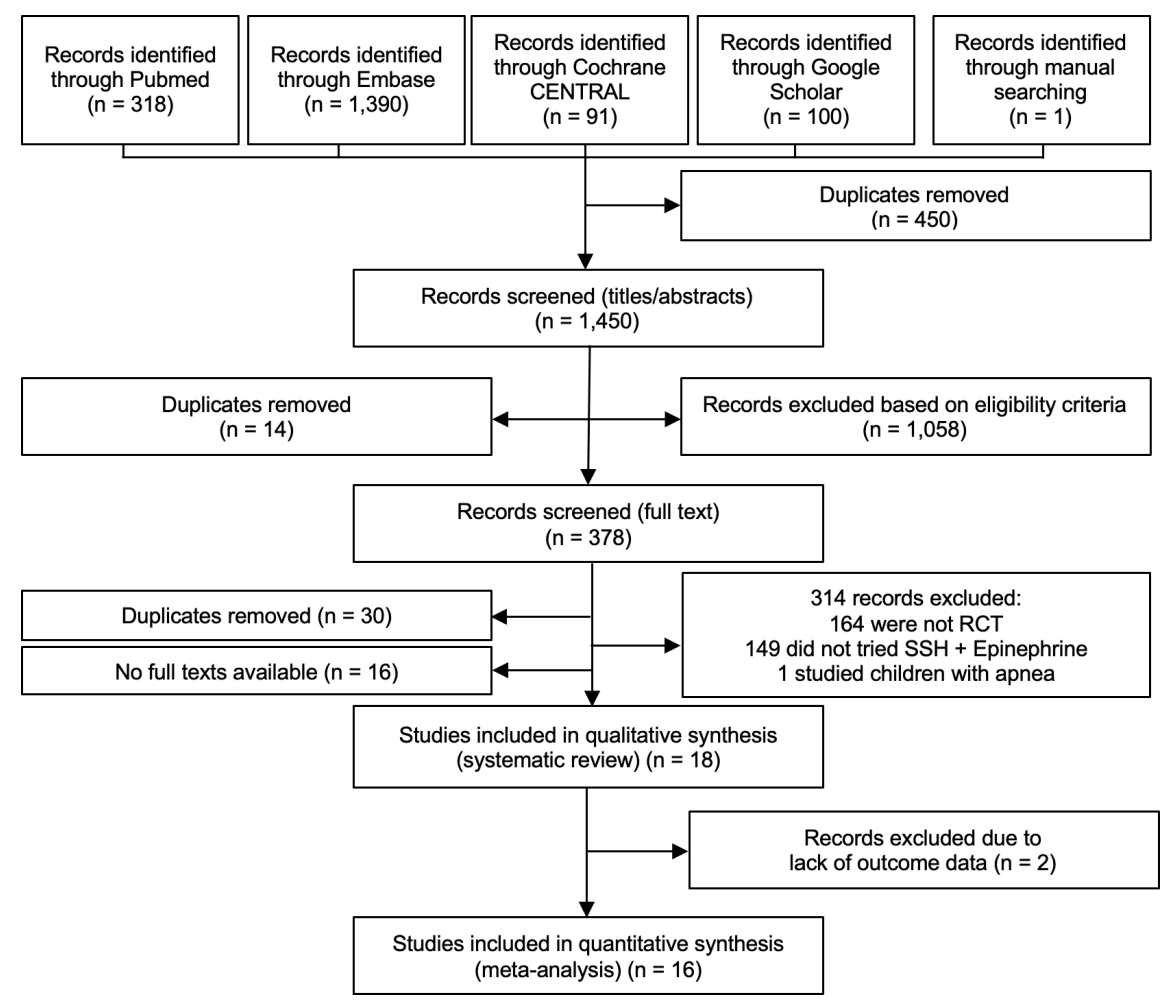

\section{Hosted file}

TABLE 1 Characteristics of included studies.pdf available at https://authorea.com/users/ 414005/articles/522155-effects-of-nebulized-epinephrine-in-association-with-hypertonicsaline-for-infants-with-acute-bronchiolitis-a-systematic-review-and-meta-analysis

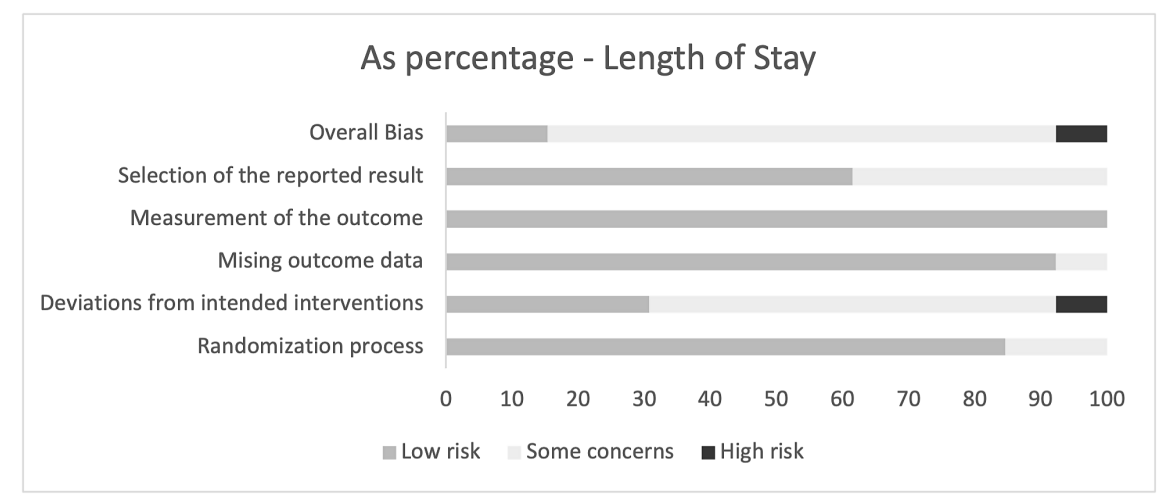



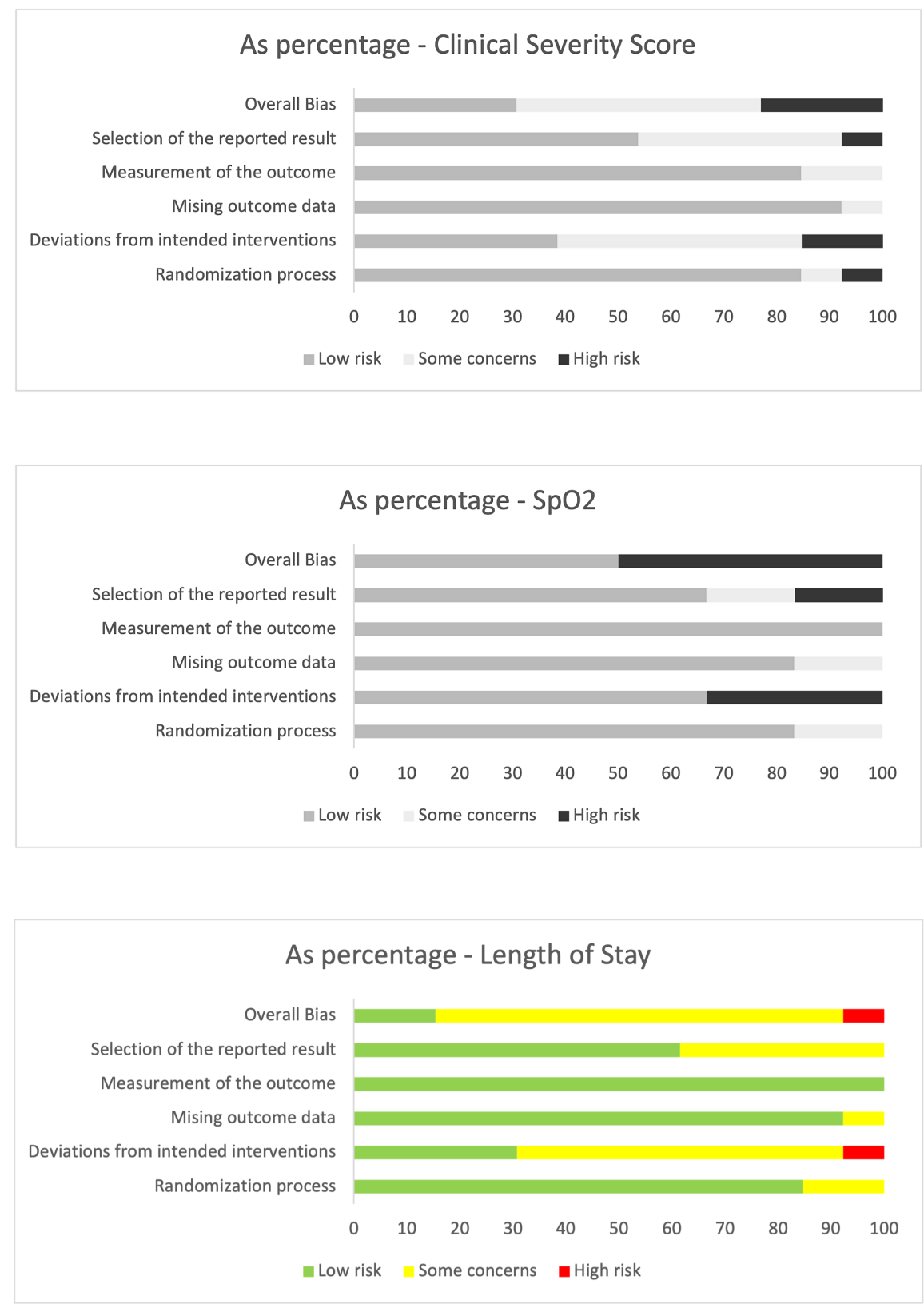

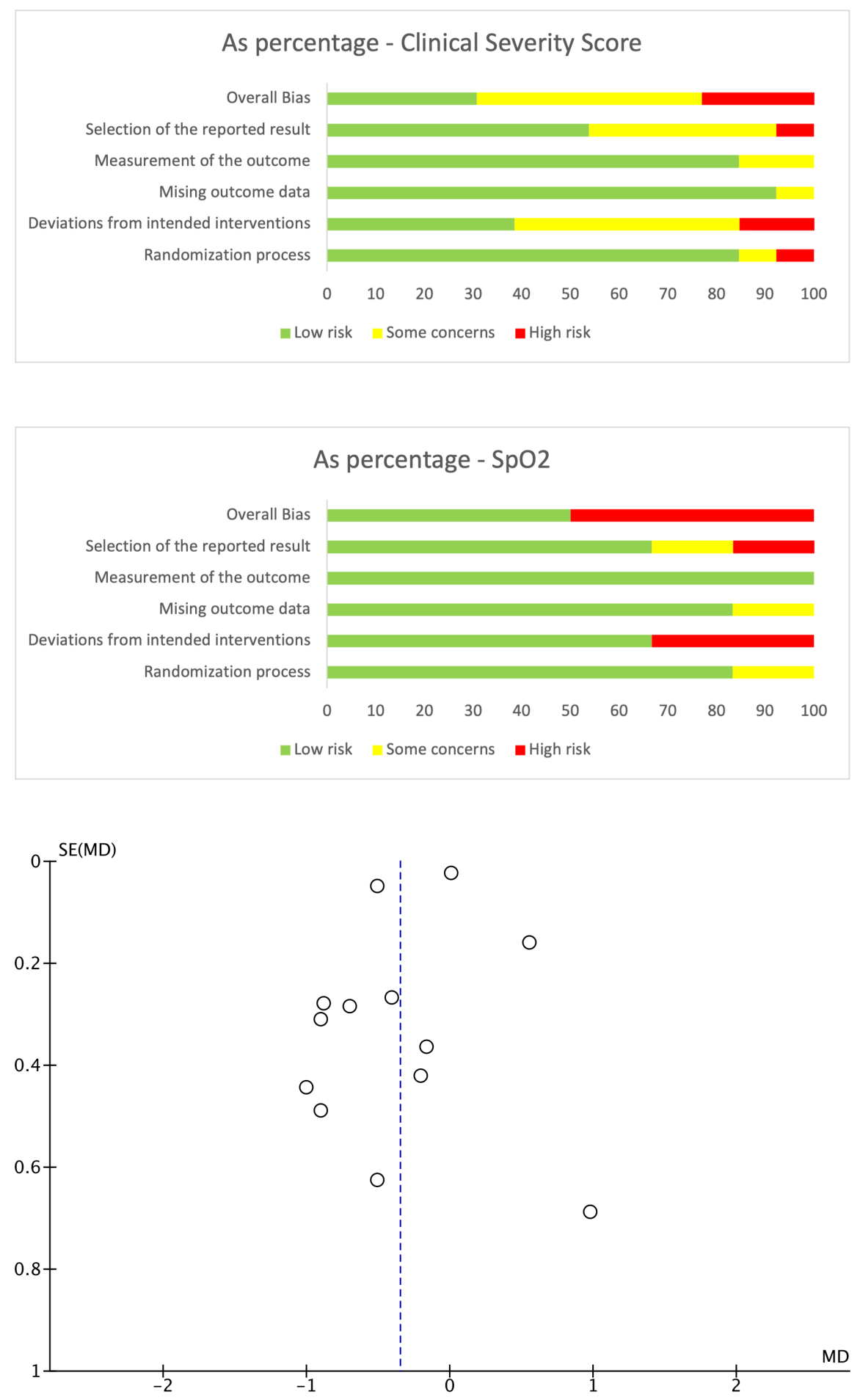

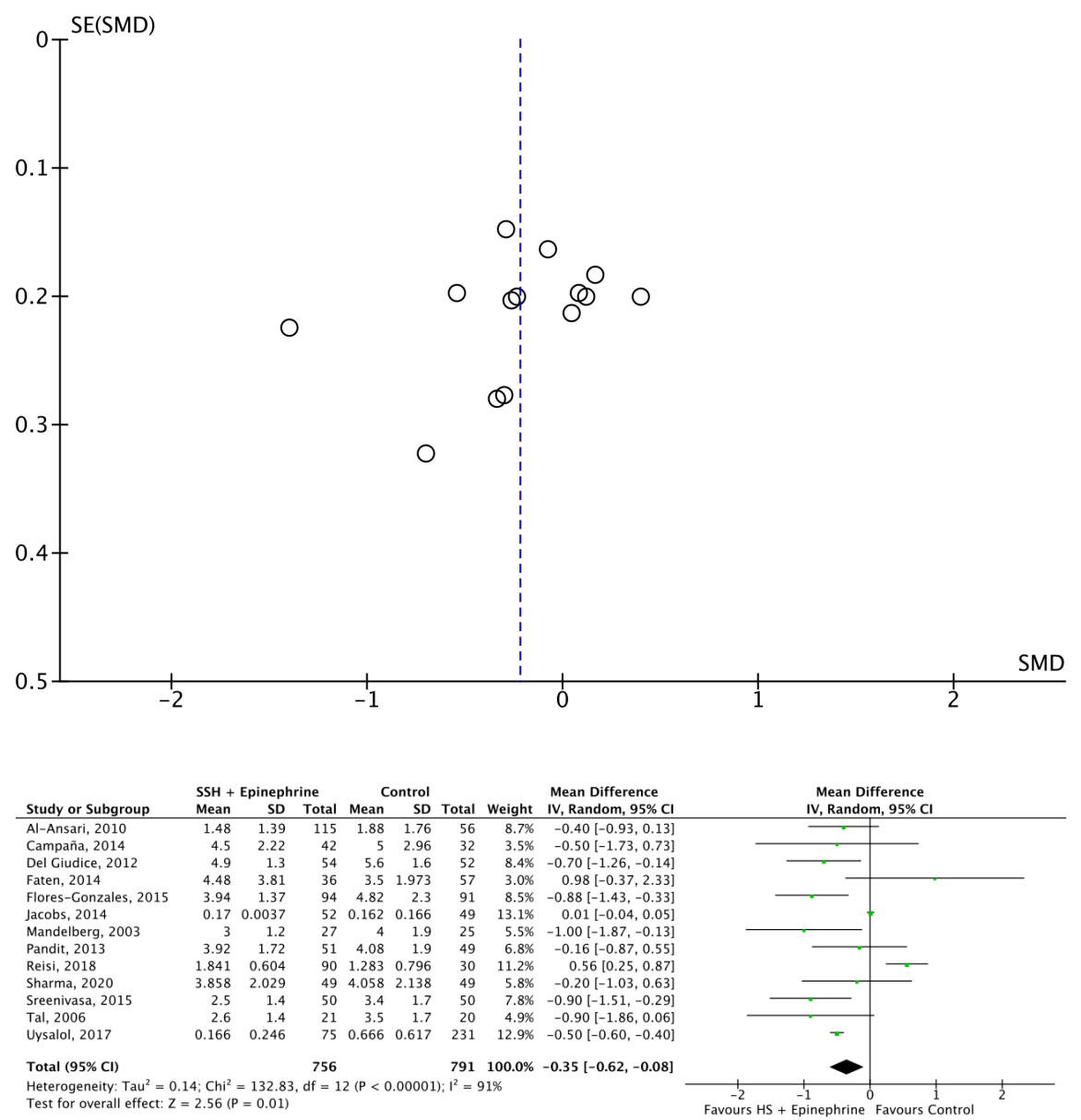

\section{Hosted file}

TABLE 2 LOS subgroup analysis.pdf available at https://authorea.com/users/414005/articles/ 522155-effects-of-nebulized-epinephrine-in-association-with-hypertonic-saline-forinfants-with-acute-bronchiolitis-a-systematic-review-and-meta-analysis 


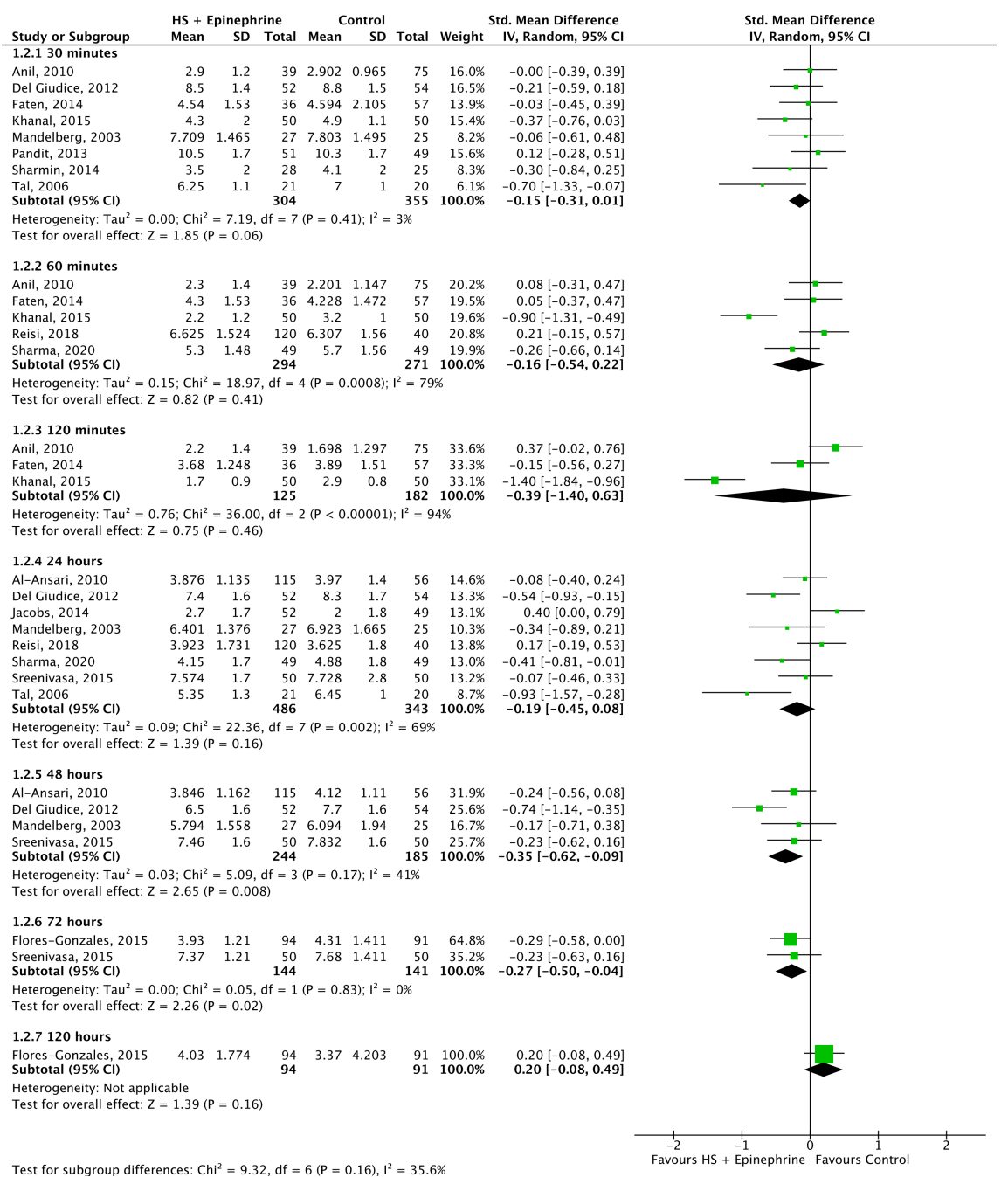

Test for subgroup differences: $\mathrm{Chi}^{2}=9.32, \mathrm{df}=6(\mathrm{P}=0.16), \mathrm{I}^{2}=35.6 \%$

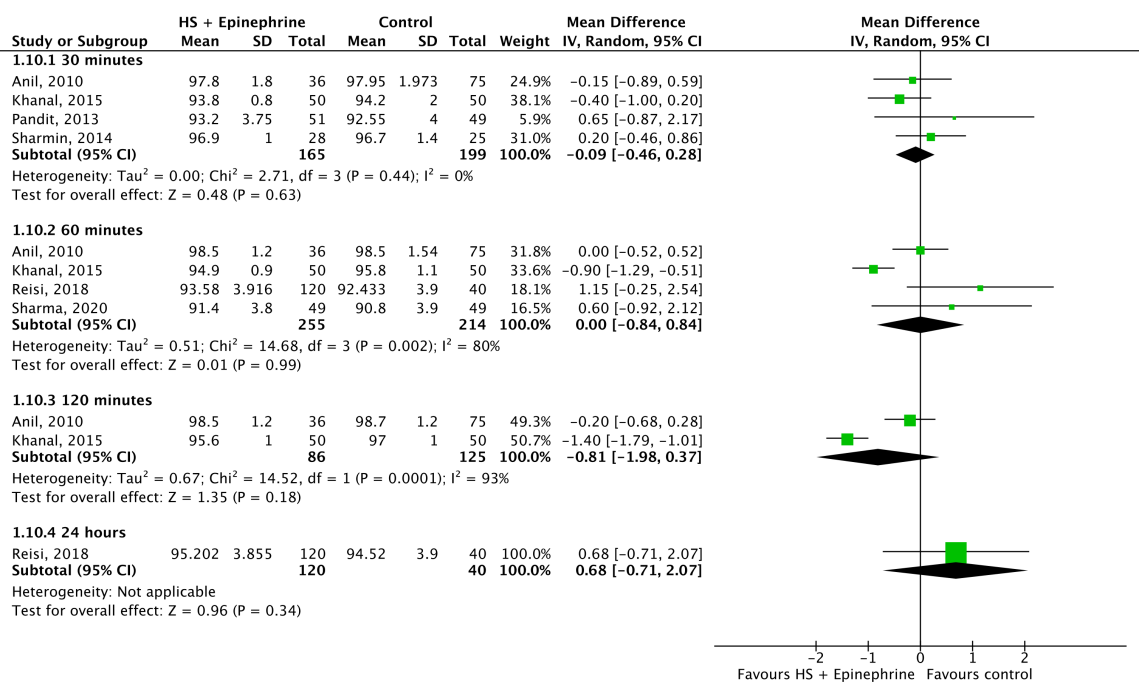

